\section{Laparoscopic Excision of a Pyloric Duplication Cyst in a Child}

Sir,

A 6-year girl presented with epigastric pain and postprandial non-bilious vomiting for the last two years. The magnetic resonance cholangiopancreatography (MRCP) confirmed a gastric duplication cyst that originated from the pylorus between the liver and stomach (Figure 1A). The mild luminal obstruction, created by the external mass on the pylorus, was observed endoscopically. The conventional three-port method was used for laparoscopy. The outward, spherical bulge from the pylorus was cystic mass, and the adherent borders to the organ were not distinguishable. This was considered a pyloric duplication cyst (PDC). The serous yellowish fluid was aspirated following the $p$ wall. Careful dissection was performed, and mucosa was stripped entirely from the cyst wall by using laparoscopic dissectors. Care was taken not to leave residual mucosal tissue. Following the complete removal of the cystic mucosal lining, omentum was pulled into the cavity, and marsupialization was not performed (Figure 1B). The resected cystic mucosa was retrieved through the umbilical trocar.

The laparoscopic surgery took 60 minutes with minimal blood loss. The patient resumed oral intake on the second postoperative day, and was discharged on the fourth day. Histopathological examination revealed a cyst fluid with benign cytology and a gastric mucosa without malignancy. At 9-month followup, there was no feeding problem, no recurrence, or any other complications.

Congenital PDC is extremely rare. ${ }^{1}$ Simple cyst excision and/or marsupialization are effective in those with normal gastric margins, but more complicated cases require various procedures, from pyloroplasty to extensive partial gastrectomy. ${ }^{2}$ It is essential to try to avoid leaving residual mucosal tissue during the operation, because the residual contents can stimulate recurrence. ${ }^{2,3}$ Although the laparoscopic approach is generally accepted due to many advantages of endoscopic surgery, no pediatric laparoscopic treatment for PDC has been reported to date. However, we think that laparoscopic unroofing and complete mucosal stripping can be performed successfully in a child with PDC. It is a safe and effective procedure, ensuring the preservation of the pyloric canal.

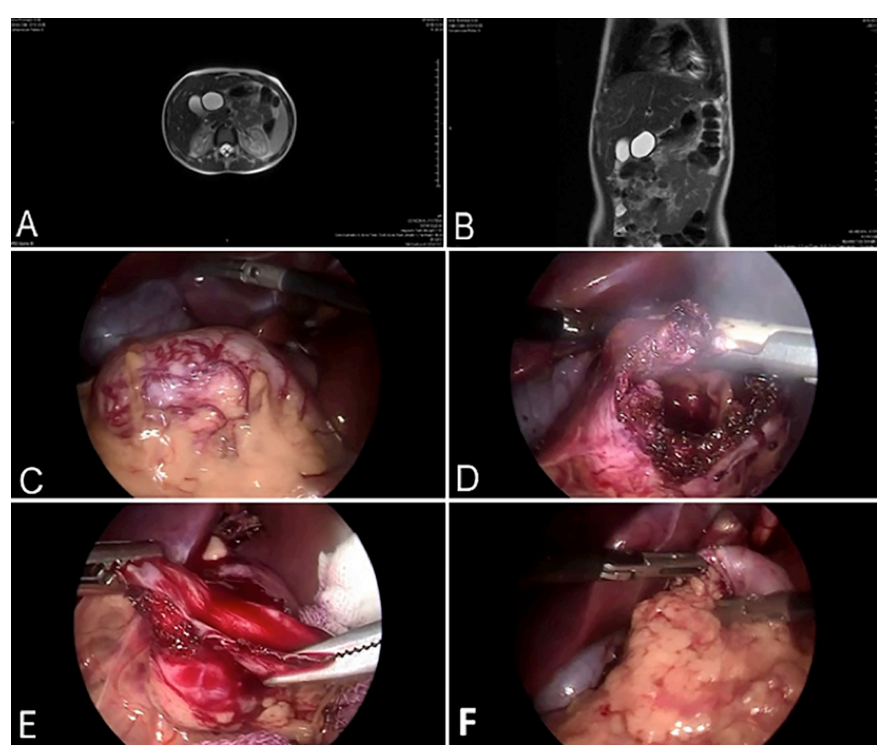

Figure 1: (A) Axial. (B) Coronal T2-weighted MR images show a wellshaped cystic mass adjacent to the gallbladder. (C) Intraoperative view of the duplication cyst location at the pylorus. (D) Unroofing. (E) Mucosal stripping. (F) Placement of omental flap

\section{CONFLICT OF INTEREST:}

The authors declared no conflict of interest.

\section{AUTHORS' CONTRIBUTION:}

EO, MK: Substantial contributions to the conception or design of the work; or the acqusition, analysis, or interpretation of data for the work; drafting the work or revising it critically for important intellectual content; and final approval of the version.

\section{REFERENCES}

1. Hattori K, Takamizawa S. Laparoscopic-endoscopic cooperative surgery for a gastric duplication cyst in the prepyloric region to preserve the pylorus ring in a child: $A$ case report. Asian J Endosc Surg 2020; 13(4):596-9. doi: 10.1111/ases.12794.

2. Balakrishnan K, Fonacier F, Sood S, Bamji N, Bostwick H, Stringel G. Foregut duplication cysts in children. JSLS 2017; 21(2):e2017.00017. doi: 10.4293/JSLS.2017.00017.

3. Ren HX, Duan LQ, Wu XX, Zhao BH, Jin YY. Laparoscopic resection of gastric duplication cysts in newborns: $A$ report of five cases. BMC Surg 2017; 17(1):37. doi: 10.1186/ s12893-017-0234-X.

Esra Ozcakir and Mete Kaya

Department of Pediatric Surgery, Bursa Medical Faculty, University of Health Sciences, Bursa, Turkey

Correspondence to: Dr. Esra Ozcakir, Department of Pediatric Surgery, University of Health Sciences, Bursa Yuksek Ihtisas Training and Research Hospital, Bursa, Turkey E-mail: dresramermer@hotmail.com 


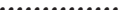

Received: October 11, 2020; Revised: June 05, 2021;
Accepted: July 12, 2021

DOI: https://doi.org/10.29271/jcpsp.2021.12.1526

$\bullet \bullet \bullet \bullet \bullet \bullet \bullet \bullet \bullet$ 